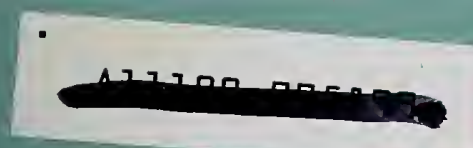

NBSIR $82-2500$
NBS PUBLICATIONS

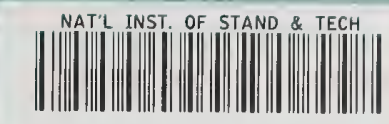

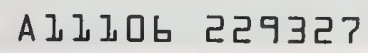

\title{
Ultrasonic Measurements of Titanium Elasticity and Attenuation in Welds and Plate
}

U.S. DEPARTIVENT OF COMMERCE

National Bureau of Stanciards

National Engineering Lacoratory

Center for Manufacturing Engineering

Ultrasonic Standards Group

Mechanical Production Merrology Division

Washington, DC 20224

May 1982

Final Peport

Piesared for:

Office of Naval Research

= QC ials Division: Code 431

100

ngton, DC 22217

.456

$32-2500$

$19: 32$

c. 2 



\section{TITANIUM ELASTICITY AND}

\section{ATTENUATION IN WELDS AND PLATE}

G. V. Blessing

U.S. DEPARTMENT OF COMMERCE

National Bureau of Standards

National Engineering Laboratory

Center for Manufacturing Engineering

Ultrasonic Standards Group

Mechanical Production Metrology Division

Washington, DC 20234

May 1982

Final Report

\section{Prepared for:}

Office of Naval Research

Materials Division: code 431

Washington, DC 22217

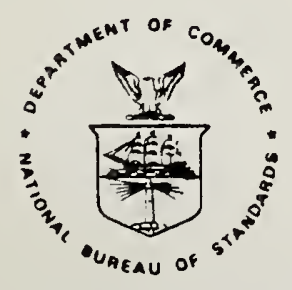

U.S. DEPARTMENT OF COMMERCE, Malcolm Baldrige, Secretary NATIONAL BUREAU OF STANDARDS, Ernest Ambler, Director 



\section{TABLE OF CONTENTS}

Abstract $\ldots \ldots \ldots \ldots \ldots \ldots \ldots \ldots \ldots \ldots \ldots \ldots \ldots \ldots \ldots \ldots \ldots \ldots \ldots \ldots$

1. Introduction $\ldots \ldots \ldots \ldots \ldots \ldots \ldots \ldots \ldots \ldots \ldots \ldots \ldots \ldots \ldots \ldots$

2. Experimental $\ldots \ldots \ldots \ldots \ldots \ldots \ldots \ldots \ldots \ldots \ldots \ldots \ldots \ldots \ldots \ldots \ldots \ldots \ldots \ldots$

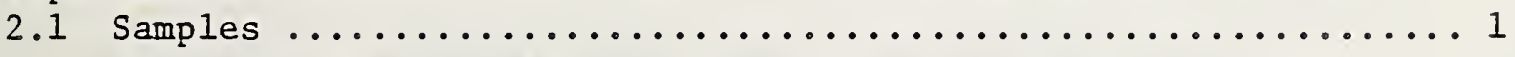

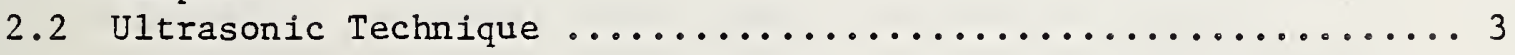

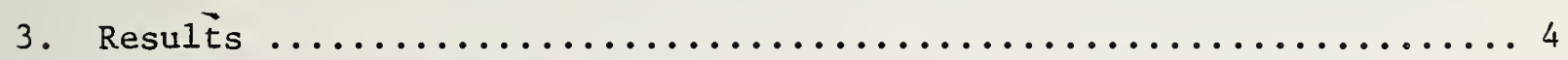

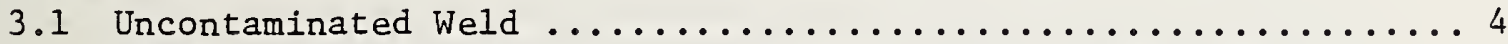

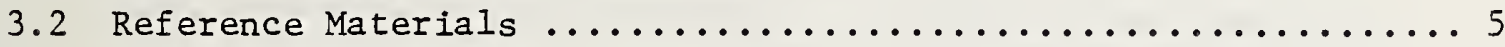

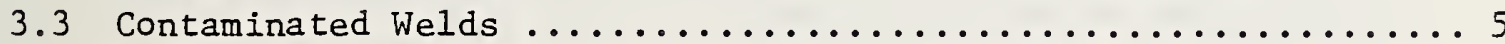

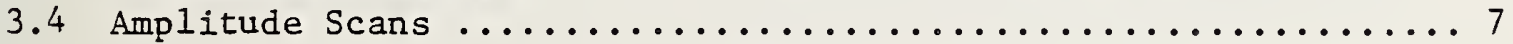

4. Conclusions $\ldots \ldots \ldots \ldots \ldots \ldots \ldots \ldots \ldots \ldots \ldots \ldots \ldots \ldots \ldots \ldots \ldots$

5. Recommendations ............................... 9

6. Acknowledgments $\ldots \ldots \ldots \ldots \ldots \ldots \ldots \ldots \ldots \ldots \ldots \ldots \ldots \ldots \ldots \ldots \ldots$

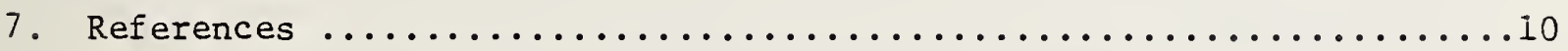




\section{LIST OF FIGURES}

Figure 1. Two magnifications of a cross-sectional view of a representative Ti 6211 weld-plate sample, etched to reveal both the epitaxial grain growth across the weld bead boundary and the plate texture.

Figure 2. Ultrasonic velocity measurement system utilizing the pulse-echo overlap technique by means of an oscilloscope delta time feature.

Figure 3. (a) A double echo train of shear waves caused by texturing in a Ti 6211 plate sample. (b) An expanded view of the first echo pair (inverted).

Figure 4. A series of C-scans at three discrete gain levels for the weldplate specimen of Figure 1, with an outline of the weld region superimposed on the third trace.

\section{LIST OF TABLES}

Table 1. Oxygen Content in Ti 6211 Alloy for Raw Material and Four Weldment Series. Numerical Values are ppm by Weight. [3].

Table 2. Ultrasonic Velocity Data (in $\mathrm{m} / \mathrm{s}$ ) as a Function of Propagation Direction $\underset{\sim}{\mathbf{k}}$ and Polarization $\underset{\sim}{\varepsilon}$ for the Uncontaminated Weld.

Table 3. Ultrasonic Velocity Data (in $\mathrm{m} / \mathrm{s}$ ) for Wave Propagation Perpendicular to the Plate.

Table 4. Ultrasonic Longitudinal Velocities (in $\mathrm{m} / \mathrm{s}$ ) in Contaminated Welds for $\underset{\sim}{\sim}$ Parallel to $\underset{\sim}{3}$.

Table 5. Ultrasonic Shear Velocities (in $\mathrm{m} / \mathrm{s}$ ) in Contaminated Welds for $\mathrm{k}$ Parallel to $\underset{\sim}{3}$ and for Polarization Directions $\underset{\sim}{1}$ and $\underset{2}{2}$. 


\section{Abstract}

Ultrasonic shear and longitudinal waves are used to evaluate the elasticity and attenuation of titanium weld and plate alloy. Wave speeds are used to measure the materials' elasticity and anisotropy, and the wave amplitude is used to measure relative levels of scattering in the weld and plate regions. Results obtained on a representative weld are compared with results obtained on oxygen contaminated specimens.

Key words: nondestructive evaluation; titanium plate; titanium welds; ultrasonic C-scan; ultrasonic velocity; weld porosity. 



\section{INTRODUCTION}

Titanium ( $T i$ ) alloy weldments are subject, during fabrication, to interstitial gas contamination which adversely affects their mechanical properties and in turn degrades structural performance. While the contamination levels which cause a problem are not well established, a need definitely exists to detect small quantities of interstitial gas nondestructively. This report presents the initial results obtained in an attempt to relate the elasticity of Ti $6211^{1}$ alloy weldments measured ultrasonically to varying degrees of sample contamination. Baseline elasticity data were obtained on "good" or representative weld and plate material, as were the relative scattering amplitudes of the ultrasonic waves. Feasibility for this approach has been demonstrated by other researchers $[1,2]$

\section{EXPERIMENTAL}

\subsection{Samples}

Ultrasonic shear and longitudinal velocity measurements were made on seven oxygen ( 0$)$ contaminated weld specimens, on an uncontaminated weld, and on plate material. The seven double-Vee butt welds were fatigue crack test specimens, fabricated with varying contamination levels by intermittent atmospheric exposure of the weldments. By this process, a concentration of interstitial 0 is expected at the surface of the approximately dozen weld beads in a given weldment. Relative contamination levels were judged in-situ by the bead coloration upon exposure. Subsequent metallurgical examination by both bulk chemical analysis and surface microprobe techniques revealed a limited correlation of 0 levels with sample coloration [3].

Table 1 compares 0 content data for the raw material and for the series of four attempted levels of contamination. The bulk chemical analyses indicate a (expected) consistently larger 0 content in the welds as compared to the raw material, with a contamination range approaching $500 \mathrm{ppm}$. The surface microprobe measurements, on the other hand, indicate a very limited increase in 0 , and for only two of the weld series.

Table 1. Oxygen Content in Ti 6211 Alloy for Raw Material and Four Weldment Series. Numerical Values are ppm by Weight [3].

\begin{tabular}{|lcccc|}
\hline Material & $\begin{array}{c}\text { Bulk Chemical } \\
\text { Analysis }\end{array}$ & $\begin{array}{c}\text { Surface Nuclear } \\
\text { Microprobe }\end{array}$ & $\begin{array}{c}\text { Coloration } \\
\text { Judgment }\end{array}$ \\
\hline Base Plate & 700 & 803 & --- \\
Weld Wire & 730 & --- & -- \\
Weld Series & 1 & 860 & 783 & Straw \\
& 2 & 780 & 770 & Yellow-Blue \\
& 3 & 980 & 860 & Blue \\
& 4 & 1190 & 915 & \\
\hline
\end{tabular}

${ }^{1} \mathrm{Ti} 6211$ is an alpha stabilized alloy with $6 \mathrm{Al}-2 \mathrm{Nb}-1 \mathrm{Ta}-0.8 \mathrm{Mo}$ percent atomic weights. 

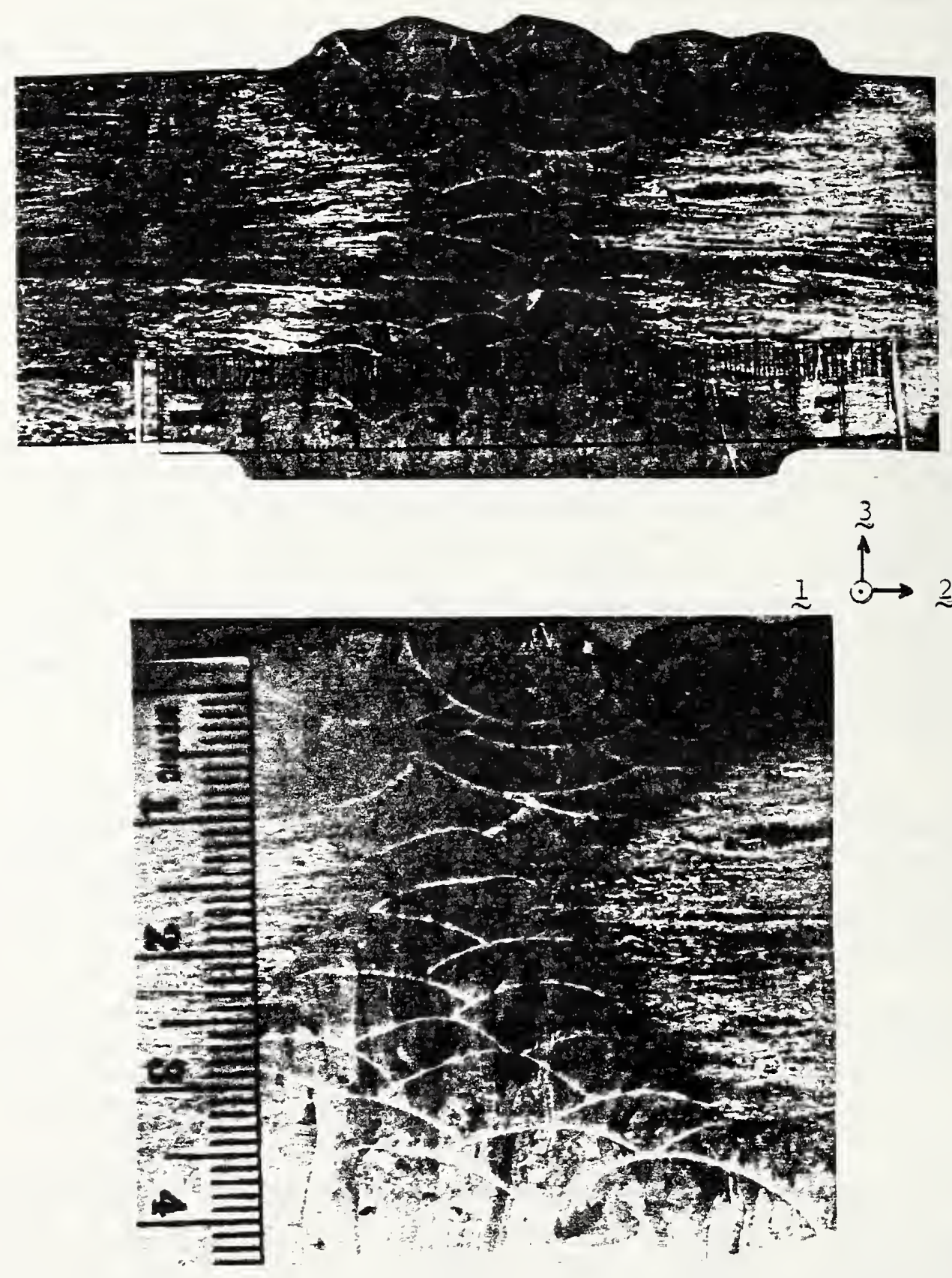

$\stackrel{3}{\leftrightarrow} \rightarrow 2$

Fig. 1. Two magnifications of a cross sectional view of a representative Ti $621 \mathrm{l}$ weld-plate sample, etched to reveal grain growth across the weld bead boundary and plate texture. 
The seven specimens for ultrasonic measurements, taken from the four weld series, were machined flat in the weld region to a thickness of $20 \mathrm{~mm}$ for fatigue tests. The specimens were fatigued prior to their ultrasonic evaluation. However, in most cases the cracks were located at the plate-weld boundary, and in no case were they judged to interfere with the velocity measurements. A cross section of the uncontaminated weld, of the same double-Vee fabrication as the contaminated specimens, is shown in Figure 1 . The $\underset{\sim}{1}, \underset{\sim}{2}$, and 3 directions respectively identify the bead, the in-plane normal to the bead, and the plate normal directions. Extensive grain growth in the 3 direction may be observed across the bead boundaries. After etching, the weld bead heat affected zones, caused by partial melting of the previous weld line during successive passes, appear as white cusps due to their contrasting phase structure. This weld region was subsequently cut from the specimen, and machined parallel and flat for the ultrasonic velocity measurements. A dry density measurement yielded a value of $4.46 \mathrm{gm} / \mathrm{cm}^{3}$, in reasonable agreement with $4.44 \mathrm{gm} / \mathrm{cm}^{3}$ calculated from the atomic weight percentages of alloy constituents.

\subsection{Ultrasonic Technique}

Longitudinal and shear wave velocities were obtained from time-of-flight measurements using the pulse echo overlap technique illustrated in Figure 2. A resolution of one part in $10^{4}$ for delta time exceeded the sample dimensional uniformity, and allowed for velocity measurements with a nominal precision of $\pm 0.1 \%$ for longitudinal waves, and $\pm 0.2 \%$ for shear waves. In general, several measurements were made across a given specimen geometry to evaluate material homogeneity. The longitudinal measurements were made by immersion using a $25 \mathrm{~mm}$ water path length, and the shear by direct contact using a high viscosity couplant. The longitudinal waveform was a 3 to 4 cycle tuned pulse at $10 \mathrm{MHz}$, and the shear a 1.5 cycle broadband pulse at $5 \mathrm{MHz}$. Both transducer elements were ceramic, the longitudinal of diameter $6 \mathrm{~mm}$ and the shear $13 \mathrm{~mm}$.

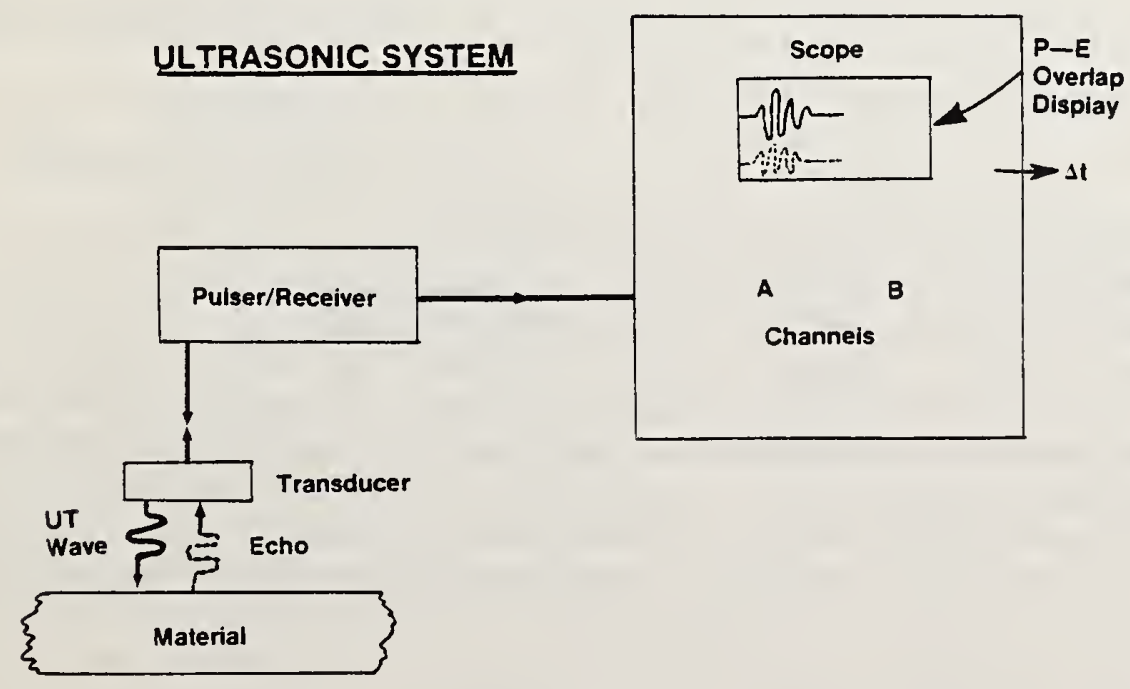

Figure 2. Ultrasonic velocity measurement system utilizing the pulse echo overlap technique by means of an oscilloscope delta time feature. 


\section{RESULTS}

A detailed evaluation of longitudinal and shear wave velocities in the uncontaminated weld will first be presented. This will be followed by the velocities obtained on the plate and two reference materials for alloy comparison and system calibration, and then on the series of contaminated welds. Finally, signal amplitude scans (C-scans) of the uncontaminated weld and plate sample will be presented.

\subsection{Uncontaminated Weld}

Table 2 summarizes the velocity results for the uncontaminated or representative weld with wave propagation $\mathrm{k}$ in the three principal directions defined in Figure 1. The first data column presents the longitudinal velocity $\left\langle\mathrm{V}_{\mathrm{L}}\right\rangle_{\mathrm{n}}$ averaged across the sample, where $\mathrm{n}$ is the number of measurements nade. The second column is the percent variation observed for each propagation direction as the $6 \mathrm{~mm}$ diameter transducer was discretely scanned across the sample surface. Two values of (extremun) shear velocities $\left\langle\mathrm{V}_{\mathrm{S}}\right\rangle_{\mathrm{n}}$ are given as a function of $\mathrm{k}$ in the next column, corresponding to a particular polarization, $\underset{\varepsilon}{\varepsilon}$ or partic ${ }_{\text {le }}$ displacement. The extrenums were observed to occur for $\varepsilon$ parallel to the respective principal directions, indicating a (not unexpected) naterial symnetry in those directions. The last column gives the percent elastic anisotropy determined from the ratio of the shear moduli 2 for the two propagation directions. While $V_{S}$ was not measured at different positions across the sample surface, one would expect the percent variation to be conparable or greater than that observed for $V_{L}$. In fact, the repeatability of the $V_{S}$ measurement was itself limited to $\pm 0.5 \%$ in some instances, showing a sensitivity to both repeat positioning and polarization orientation.

Table 2. Ultrasonic Velocity Data (in $\mathrm{n} / \mathrm{s}$ ) as a Function of Propagation Direction $\underset{\sim}{\sim}$ and Polarization $\underset{\sim}{\varepsilon}$ for the Uncontaminated Weld.

\begin{tabular}{|c|c|c|c|c|}
\hline$\underset{\mathrm{k}}{\sim}$ & $\mathrm{V}_{\mathrm{L}}$ & $\%$ Variation & $\mathrm{V}_{\mathrm{S}}(\underline{\varepsilon})$ & $\%$ Anisotropy \\
\hline 1 & $\langle 6150\rangle_{6}$ & 0.08 & $\langle 3168\rangle_{2}\left(\frac{2}{3}\right)$ & 2. \\
\hline 2 & $\langle 6158\rangle_{4}$ & 0.15 & $\langle 3168\rangle_{4}\left(\frac{1}{3}\right)$ & 0.3 \\
\hline 3 & $\langle 6153\rangle_{6}$ & 0.05 & $\begin{array}{l}\langle 3183\rangle_{3}(\underset{2}{1}) \\
\langle 3174\rangle_{3}(\underset{2}{2})\end{array}$ & 0.5 \\
\hline
\end{tabular}

The large velocity variations for propagation in a given direction, reflecting material inhomogeneity, prevent us from making a detailed comparison of the elasticity as a function of direction. Qualitatively we can say that the longitudinal velocity, which is dominated by the compressional elasticity, varies little as a function of direction. The shear velocity (and therefore modulus) varies much more, as a function both of propagation and polarization direction, with a maximum anisotropy occurring for $\underset{\sim}{\sim}$ parallel to the $\underset{\sim}{\sim}$ directicn. Much of the shear data can be explained by assuming a unidirectional symetry model with the direction of maximum stiffness lying in the $(\underset{\sim}{2}, 3)$ plane, near the 3 direction. This assumption for the weld texture is consis- 
tent with metallurgical examinations which reveal grain growth in the 3 direction, and with an expected component of dendritic growth along the bead ( 1 ) direction.

\subsection{Reference Materials}

It is of interest to compare the weld elasticity with the raw plate material and with another titanium alloy. The data for Ti 6211 and a more common alloy $\mathrm{Ti} 6 \mathrm{Al} 4 \mathrm{~V}$ plate are given in Table 3 for wave propagation perpendicular to the plane of the plate. In addition, velocity values obtained in a single crystal of $X$-cut quartz are presented as reference points for system accuracy and subsequent measurement precision. The longitudinal data show an approximate one percent increase in compressional modulus for the plates compared to the weld. In $\mathrm{Ti}$ 6211, both the stiffer shear component and the anisotropy are greater in the plate than in the weld. One plate specimen

(attached to weld 16 ) revealed an anisotropy of $6.5 \%$ which illustrates itself by the double-echo pattern of Figure 3. The separation of the incident shear energy ( $k$ perpendicular to the rolled plate) into two distinct modes of wave propagation is easily observed, revealing substantial plate texturing. Finally, wave velocities measured parallel to the plane of Ti 6211 plate yielded values comparable to those in Table 3.

Table 3. Ultrasonic Velocity Data (in $\mathrm{m} / \mathrm{s}$ ) for Wave Propagation Perpendicular to the Plate.

\begin{tabular}{|c|c|c|c|c|c|}
\hline Material & $\mathrm{v}_{\mathrm{L}}$ & $\%$ & Variation & $\mathrm{v}_{\mathrm{S}}$ & $\%$ Anisotropy \\
\hline Ti 6211 Plate & $\langle 6196\rangle_{6}$ & & 0.13 & $\begin{array}{l}\langle 3179\rangle_{2}\left(\begin{array}{l}1 \\
(2) \\
\langle 3220\rangle_{2}(2)\end{array}\right.\end{array}$ & 2.6 \\
\hline Ti 6Al4V Plate & $\langle 6191\rangle_{2}$ & & -- & $\begin{array}{l}3190 \text { (点) } \\
3194 \text { (2) }\end{array}$ & 0.2 \\
\hline Quartz X-cut & $\langle 5752\rangle_{4}$ & & -- & 3299 (slow & mode) --- \\
\hline
\end{tabular}

\subsection{Contaminated Welds}

Table 4 lists the longitudinal velocities obtained on the seven contaminated welds for wave propagation in the 3 direction. The specimens have two digit descriptors, the first corresponding to the weld series and the second to the particular sample cut from the parent series. While a measurement precision of $0.06 \%$ is able to differentiate a relatively low velocity value for specimen 22, the large variations observed within each sample preclude ascribing much significance to that difference. The results were similar for the shear velocities ( $0.1 \%$ measurement precision) given in Table 5: no correlation of wave speed with weld series could be observed.

${ }^{2}$ hear Modulus $=$ Density $\times \mathrm{v}_{\mathrm{S}}{ }^{2}$ 

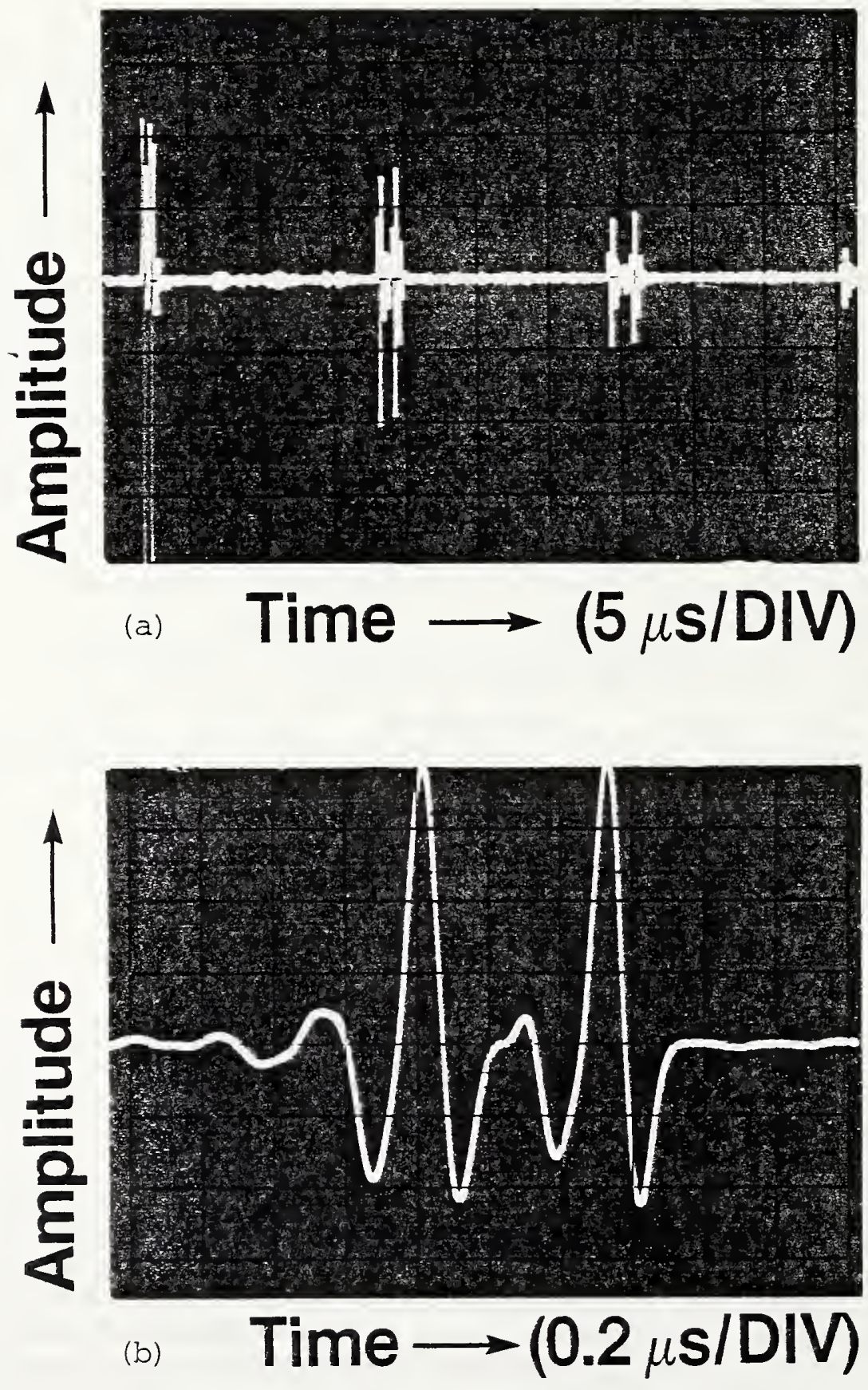

Fig. 3. (a) A double echo train of shear waves caused by texturing in a Ti 6211 plate sample. (b) An expanded view of the first echo pair (inverted). 
Table 4 Ultrasonic Longitudinal Velocities (in $\mathrm{m} / \mathrm{s}$ ) in Contaminated Welds for $\underset{\sim}{*}$ Parallel to 3 .

\begin{tabular}{|c|c|c|}
\hline Specimen & $\left\langle\mathrm{V}_{\mathrm{L}}\right\rangle_{6}$ & \% Variation \\
\hline 16 & 6180 & 0.5 \\
22 & 6167 & 0.3 \\
24 & 6178 & 0.1 \\
35 & 6181 & 0.2 \\
36 & 6180 & 0.2 \\
45 & 6180 & 0.1 \\
46 & 6180 & 0.2 \\
\hline
\end{tabular}

Table 5 Ultrasonic Shear Velocities (in $\mathrm{m} / \mathrm{s}$ ) in Contaminated Welds for $\underset{\sim}{\mathrm{k}}$ Parallel to $\underset{\sim}{2}$ and for Polarization Directions $\underset{\sim}{2}$ and $\underset{\sim}{2}$.

\begin{tabular}{|c|c|c|c|}
\hline Specimen & $\mathrm{v}_{\mathrm{S}}(\underset{\sim}{(1)}$ & $\mathrm{v}_{\mathrm{S}}(\underset{\sim}{2})$ & \% Anisotropy \\
\hline 16 & 3211 & 3193 & 1.5 \\
22 & 3216 & 3188 & 1.0 \\
24 & 3214 & 3187 & 1.1 \\
35 & 3216 & 3192 & 1.5 \\
36 & 3216 & 3197 & 0.9 \\
45 & 3215 & 3198 & 0.9 \\
\hline 46 & 3215 & 3190 & 1.1 \\
\hline
\end{tabular}

\subsection{Amplitude Scans}

In addition to the velocity measurements, a series of pulse-echo backwall reflection scans (C-scans) were made on the reference weld-plate specimen, with wave propagation in the $\frac{1}{\sim}$ direction. A $10 \mathrm{MHz}$ transducer focused at 300 $\mathrm{mm}$ in water was used for enhanced lateral resolution. Two significant features in the three representative C-scans of Figure 4 deserve attention. The first is a greater attenuation of ultrasound in the plate than in the weld, which contrasts sharply with the situation commonly observed in austenitic steels. For example, while the plate region has become nearly opaque to ultrasound at the $-34 \mathrm{~dB}$ gain setting, the weld region remains identifiable. 


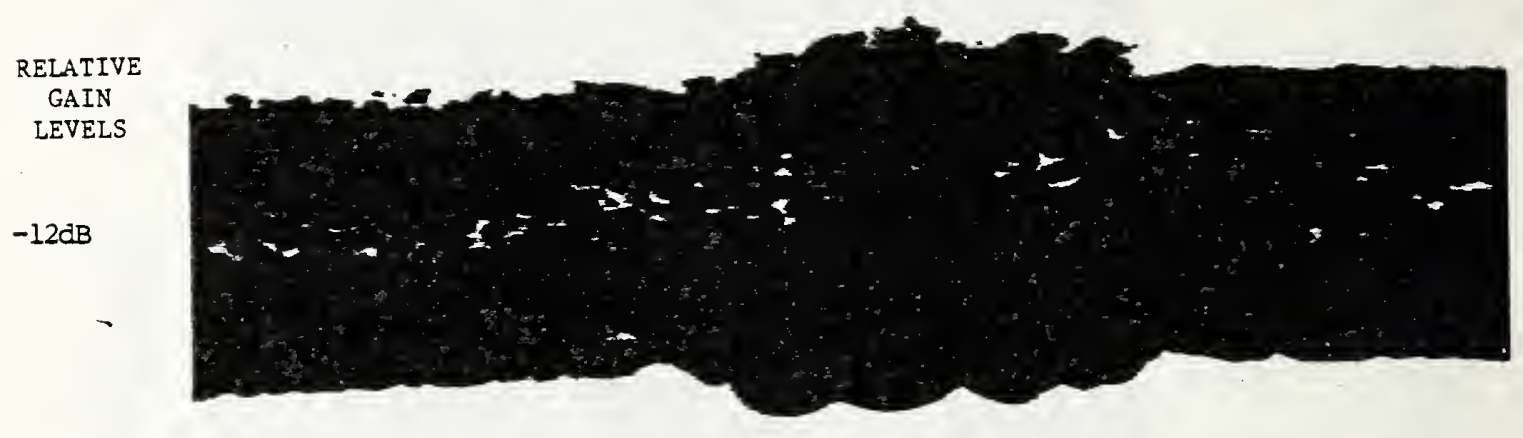

$-22 \mathrm{~dB}$

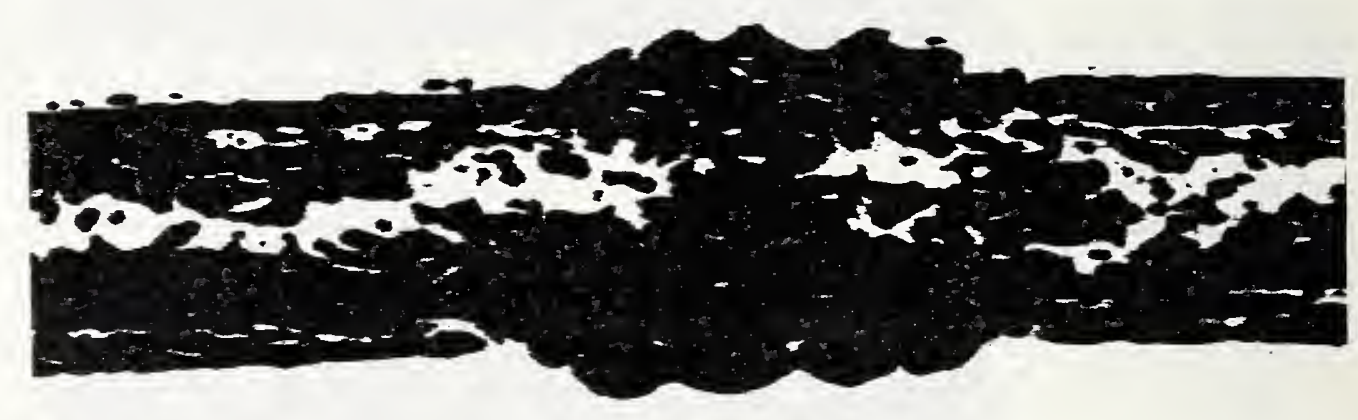

$-34 d 8$

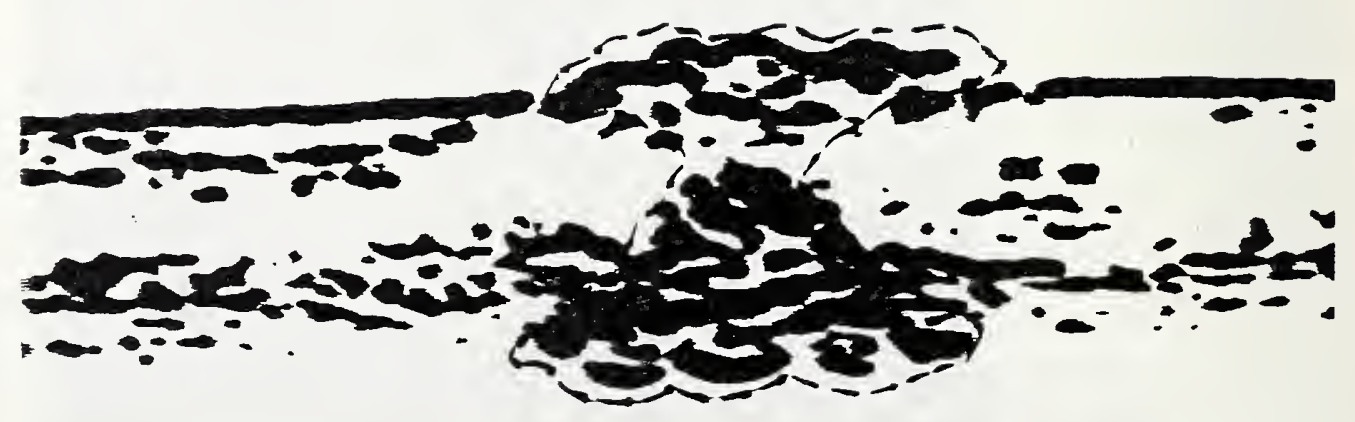

Fig. 4. A series of C-scans at three discrete gain levels for the weld-plate specimen of Fig. I, with an outline of the weld region superimposed on the third trace. 
The second feature is the large range in signal amplitude for both the plate and weld regions. A total range of about $30 \mathrm{~dB}$ from initial ultrasonic penetration to complete transmission was observed at this frequency and sample thickness.

Relative amplitude measurements were also made for wave propagation at discrete positions in the 3 direction. Again the plate was observed to have a much larger attenuation than the weld, by about a factor of two.

\section{CONCLUSIONS}

Ultrasonic shear and longitudinal wave velocity measurements on a representative $\mathrm{Ti} 6211$ weldment revealed an anisotropy due to preferential grain growth, implying an elastic axis of symmetry to lie between the bead direction and a perpendicular to the plane of the welded plates. A comparison with the plate elasticity showed slightly less stiffness (approximately one percent) and a smaller anisotropy. The elastic anisotropy due to texturing in the rolled plate was very noticeable, in one case exceeding six percent. Amplitude measurements by both direct contact and immersion C-scan revealed an appreciably greater attenuation in the plate than in the weld for the $0.5 \mathrm{~mm}$ ultrasonic wavelengths employed.

Perhaps the greatest challenge to the ultrasonic inspection of $\mathrm{Ti} 6211$ alloy is the material variability or inhomogeneity that exists on the scale of ultrasonic wavelengths normally employed. For example, sound speed differences that might be readily detected with available measurement precision, and related to sample contamination levels, were in fact overwhelmed by variations within the samples themselves at 5 and $10 \mathrm{MHz}$. No correlation of weld sound speed with the limited 0 contamination levels could be observed for the sample set provided. However, inconsistent contamination level analyses raises a question for sample veracity. It is encouraging to note that the contaminated weld sound speeds were consistently larger than that for the uncontaminated weld. This is expected for titanium additionally hardened by an increased alpha phase level via interstitial 0 stabilization.

\section{RECOMMENDATIONS}

A primary recommendation for future work is to generate a well characterized sample set possessing a large range of contamination levels, especially to include the worst case level. In addition to the approach taken here, the temperature and frequency dependence of ultrasonic wave propagation may be worth pursuing. For example, elevated temperature studies may reveal a greater sensitivity of the sound speed to gaseous contamination as the matrix elasticity is reduced. Secondly, using a lower frequency (larger wavelength) would serve to desensitize the elasticity measurements to the effects of large grains and texturing while remaining sensitive to interstitial gas content.

\section{ACKNOWLEDGEMENTS}

The author wishes to acknowledge fruitful discussions with Prof. R. E. Green, Jr. of Johns Hopkins University, and Dr. N. N. Hsu of the National Bureau of Standards. This work was supported by the Naval Research Laboratory, Code 8531, Washington, D. C. 


\section{REFERENCES}

1. Hsu N.; Conrad, H. Ultrasonic wave velocity measurements on titanium-oxygen alloys, Scripta Metallurgica 5: 905-908; 1971.

2. Buck, 0.; Thompson, D. 0.; Paton, N. E.; Williams, J. C. The relation between internal friction spectra and the athermal $\beta \rightleftarrows \omega$ transformation in $\mathrm{Ti}-\mathrm{V}, \mathrm{Ti}-\mathrm{V}-\mathrm{O}$, and Ti-V-H alloys. Proc. of the fifth intern. conf. on internal friction and ultrasonic attenuation in crystalline solids; 1973 August 27-30; Aachen, Germany. 451-458.

3. Hardy, R. Jr., Toughness of air contaminated Ti 6Al-2Nb-1Ta-0.8Mo, David Taylor Naval Ship Res. and Develop. Center (U.S.)

Internal Repport SME-79/34; 1979. 16p. 
NBS.114A (REV. 2.8C)

U.S. OEPT. OF COMM.

BIBLIOGRAPHIC DATA

SHEET (See instructions)

4. TITLE AND SUBTITLE

Ultrasonic Measurements of Titanium 6211 Weld and Plate
1. PUBLICATION OR REPORT NO. NBSIR $82-2500$

\section{TITLE AND SUBTITLE}

2. Performing Organ. Report Nof 3. Publication Date

May 1982

Ultrasonic Measurements of Titanium 6211 Weld and Plate
5. $A U T H O R(S)$
G.V. Blessing

6. PERFORMING ORGANIZATION (If joint or other than NBS, see in structions)

NATIONAL BUREAU OF STANDARDS

DEPARTMENT OF COMMERCE

WASHINGTON, D.C. 20234

7. Contrace/Grant No.

9. SPONSORING ORGANIZATION NAME AND COMPLETE ADDRESS (Street, City, Stote, ZIP)

8. Type of Report \& Period Covered Final

Office of Naval Research

Materials Division: Code 431

Washington, DC 22217

10. SUPPLEMENTARY NOTES

Document describes a computer program; SF-185, FIPS Software Summary, is attached.

11. ABSTRACT (A 200-word or less factual summan of most significant infomation. If document includes a significant bibliography or literature survey, mention it here)

Ultrasonic shear and longitudinal waves are used to evaluate the elasticity and attenuation of titanium weld and plate alloy. Wave speeds are used to measure the materials' elasticity and anisotropy, and the wave amplitude is used to measure relative levels of scattering in the weld and plate regions. Results obtained on a representative weld are compared with results obtained on oxygen contaminated specimens.

12. KEY WORDS (Six to twelve entries; alphabetical order; capitalize only proper names; and separate key words by semicolons) nondestructive evaluation; titanium plate; titanium welds; ultrasonic C-scan; ultrasonic velocity; weld porosity. 20402.

14. NO. OF PRINTED PAGES

15

15. Price

$\$ 6.00$

X Order From National Technical Information Service (NTIS), Springfield, VA. 22161 

